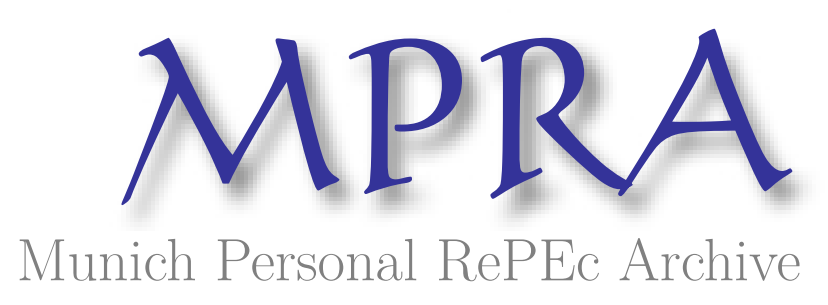

\title{
A Game-Theoretic Model of Water Theft During a Drought
}

Batabyal, Amitrajeet and Beladi, Hamid

Rochester Institute of Technology, University of Texas at San Antonio

6 September 2020

Online at https://mpra.ub.uni-muenchen.de/108346/

MPRA Paper No. 108346, posted 21 Jun 2021 22:35 UTC 


\section{A Game-Theoretic Model of Water Theft During a Drought ${ }^{1}$}

by

\section{AMitraJEeT A. BATABYAL ${ }^{2}$}

and

HAMID BELADI ${ }^{3}$

1

For their helpful comments on a previous version of this paper, we thank the Editor-in-Chief Xiying Zhang, the Associate Editor Francisco Alcon, two anonymous reviewers, and session participants in (i) the Australian Agricultural and Resource Economics Society Virtual Annual Conference in February 2021, (ii) the Western Regional Science Association Virtual Annual Meeting in February 2021, (iii) the Southern Regional Science Association Virtual Annual Conference in April 2021, and (iv) the Regional Science Association International Virtual World Congress in May 2021. Batabyal acknowledges financial support from the Gosnell endowment at RIT. The usual disclaimer applies.

2

Department of Economics, Rochester Institute of Technology, 92 Lomb Memorial Drive, Rochester, NY 14623-5604, USA. Email: aabgsh@rit.edu

3

Department of Economics, University of Texas at San Antonio, One UTSA Circle, San Antonio, TX 78249-0631, USA. E-mail: Hamid.Beladi@utsa.edu 


\title{
A Game-Theoretic Model of Water Theft During a Drought
}

\begin{abstract}
We study water use by two geographically proximate farmers in a particular region during a drought. The two farmers each have an endowment of time that can be used either to produce water or to steal water. The price of water is exogenously given. The goal of the two farmers is to maximize their wealth from water production and water theft. In this setting, we perform three tasks. First, we determine the Nash equilibrium of the game-theoretic interaction between the two farmers. Second, we study how this equilibrium depends on the ease with which water can be stolen. Finally, we show how the preceding equilibrium is impacted when there is no water theft and then we determine the maximum amount that a farmer would be willing to pay to prevent theft.
\end{abstract}

Keywords: Drought, Nash Equilibrium, Static Game, Water Theft, Willingness to Pay

JEL Codes: Q25, D74 


\section{Introduction}

There is no gainsaying the fact that water is a critical input for agricultural production and therefore it plays a key role in food security. Irrigated agriculture represents 20 percent of the total cultivated land and it contributes 40 percent of the total food produced worldwide. ${ }^{4}$ Studies---see Tilahan et al. (2011) and Sampaio Morais et al. (2021)---show that on average, irrigated agriculture is at least twice as productive per unit of land as rain-fed agriculture. Therefore, this kind of agriculture permits greater production intensification and crop diversification.

A drought is normally defined as a natural hazard caused by a period of abnormally low precipitation. ${ }^{5}$ As pointed out by Wilhite (2007), Knox et al. (2010), and Rey et al. (2017), agriculture is one of the sectors that suffers most from the consequences of droughts, which are responsible for the greatest loss of agricultural production in many countries. In fact, the effects of drought on agriculture are becoming an important abiotic stress in the temperate and humid regions of the world.

Within the agricultural sectors of many nations, droughts have given rise to abnormal behavior by farmers. In fact, as pointed out by Brisman et al. (2018) and Loch et al. (2020), in many societies, the acute scarcity of water during droughts has frequently resulted in farmers turning on each other and, in the process, stealing water. ${ }^{6}$ For instance, in 2008 , the government of the state of Uttar Pradesh in India charged over 2000 farmers in the drought stricken region of

\footnotetext{
4 Go to https://www.worldbank.org/en/topic/water-in-agriculture for additional details. Accessed on 26 May 2021. 5 Go to https://www.weather.gov/bmx/kidscorner_drought for more details. Accessed on 26 May 2021. 6 Also see https://www.weforum.org/agenda/2020/09/global-water-theft-report-agriculture/ for more details. Accessed on 27 May 2021.
} 
Bundelkhand with stealing water. ${ }^{7}$ This action led to protests by local farmers and politicians who argued that water ought to be available to all at no cost, an economically unsound perspective ${ }^{8}$ that has nonetheless proved to be a popular viewpoint in certain quarters. ${ }^{9}$

Distinguishing between access and rights to water, Pradhan and Pradhan (2000) and Meinzen-Dick (2014) discuss instances in the hills of Nepal in which irrigators from one system have permitted farmers from another area to use water as long as the farmers from the second system did not claim rights to this water. However, the provision of access has often not been sufficient for this second group of farmers who have used a range of strategies such as water diversion and outright theft to claim rights to the water. Khokha (2015) points out that in Madera County, California, in the United States, as wells have gone dry and water prices have soared, water theft from farmers, including the theft of water hoses, the copper wiring, and water pumps, has become commonplace. In Muzaffargarh, Pakistan, upstream farmers and, surprisingly, senior irrigation officials, have been charged with stealing water from canals and thereby disadvantaging downstream farmers. ${ }^{10}$ Finally, Viellaris (2019) points out that in Toowoomba, Australia, desperate farmers have turned on each other, stealing water from dams, tanks, household taps, and that these activities are tearing communities apart. ${ }^{11}$

\footnotetext{
7 Go to https://www.circleofblue.org/2008/world/hot-water-lands-farmers-in-hot-water/ for more details. Accessed on 26 May 2021. 8 Go to https://blog.nationalgeographic.org/2012/08/29/the-high-costs-of-free-water/ for additional details. Accessed on $27 \mathrm{May}$ 2021.

9

Go to https://www.circleofblue.org/2013/world/scarcity-in-a-time-of-surplus-free-water-and-energy-cause-food-waste-and-

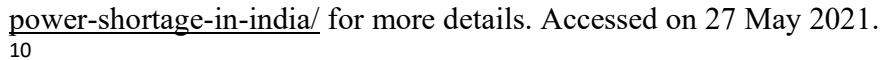

Go to https://www.dawn.com/news/1484809/farmers-complain-about-canal-water-theft for more details. Accessed on 26 May 2021 . 
As the above examples and the work of Lowdermilk (1990) demonstrate, during a drought, the phenomenon of water theft by farmers and farmers turning on each other is now quite common. Even so, to the best of our knowledge, this issue has received very little empirical or theoretical attention in the literature. Focusing first on two empirical studies, Ray and Williams (1999) use a mathematical programming model to analyze water use by upstream and downstream farmers from canals in the state of Maharashtra, India. They show that even though water theft increases the social cost of price policies, these same policies induce upstream farmers to steal water and hence leave downstream farmers with less water and lower incomes. In a later study of a canal in Maharashtra state, India, Ray and Williams (2002) once again use a mathematical programming model to analyze the extent to which farmers voting to cooperate can solve the problem of water theft. Their study shows that because the gains and the losses from cooperation are spatially distributed, voluntary bargaining will rarely achieve an efficient allocation of water.

Will a system of tradable water rights attenuate conflicts arising from the contested use of water? Galaz (2004) uses game-theoretic reasoning coupled with empirical evidence to shed light on this question in the context of Chile. On the basis of his analysis, he contends that the introduction of a water market in Chile has given rise to an "obvious incentive" to violate the water rights of underprivileged users. Podimata and Yannopoulos (2015) provide a nice overview of some of the ways in which game theory has been used to analyze issues concerning water use and conflicts stemming from the use of water. Specifically, these authors highlight the evolution of game theory applications in irrigation and they comment on the ways in which resource conflicts stemming from irrigated agriculture might be resolved. The above two papers have certainly advanced our understanding of some of the ways in which game theory can be used to shed light on water use related conflicts. Even so, to the best of our knowledge, the extant literature has not 
studied a drought environment in which farmers are tasked with ascertaining (i) how much of their fixed endowment of time they would like to use to either produce or to steal to water and (ii) how these "produce" and "steal" decisions affect their wealth, which they would like to maximize.

Given this lacuna in the extant literature, our objective in this paper is to provide a rigorous, game-theoretic analysis of water use by two geographically proximate farmers in a particular region during a drought. The game-theoretic model we work with in this paper is useful and therefore important because of three reasons. First, this model makes transparent the ways in which strategic considerations on the part of farmers influence their decisions to produce and steal water. Second, the model points out how exogenous factors such as the endowment of time available to the farmers and the ease with which water can be stolen affect their decision to produce and steal water. Finally, the model demonstrates how a policymaker might design an incentive scheme that tells us how much farmers would be willing to pay to avoid the theft of water.

\section{The Theoretical Framework}

Consider two geographically proximate farmers who grow the same crop in a particular region during a drought. Each of these two farmers has a total of $T>0$ hours to allocate between water production and water theft. For the ultimate purpose of crop cultivation, the input water can be "produced" in a variety of ways. These include the construction of a tube well, the storage of water in tanks that are filled by tankers, and drawing water from one or more canals. Similarly, water can be stolen by illegally using the other farmer's tube well to draw water, by directly removing water from a tank, and by illegally diverting water from one or more canals. Since these two farmers produce the same crop and they are located close to each other in space, we suppose that they are very similar in terms of their abilities to both produce and steal water. This means that in the ensuing formal analysis, it makes sense to analyze a symmetric Nash equilibrium. That 
said, it should be noted that if the If the two farmers have dissimilar abilities as far as the production and the theft of water are concerned then it would make sense to study an asymmetric Nash equilibrium.

The production process generates output of water $\left(q_{p}\right)$ in accordance with the logarithmic production function

$$
q_{p}=\log \left(\tau_{p}\right)
$$

where $\tau_{p}>0$ denotes the amount of time spent producing water. ${ }^{12}$ If time $\tau_{t}>0$ is the time devoted to stealing water by one farmer then a fraction $\zeta \tau_{t} / T$ of the other farmer's output of water can be stolen. The parameter $\zeta>0$ describes the ease with which water can be stolen by either of the two farmers. Each unit of water has an exogenously given price $p>0$. The goal of both farmers in our model is to maximize their wealth from water production and theft. With this description of the theoretical framework out of the way, our next task is to ascertain the Nash equilibrium---see Nash (1951)---of the static game-theoretic interaction between the two farmers. ${ }^{13}$

\section{The Nash Equilibrium}

We begin by mathematically delineating the value of the output of water produced by farmer 1 . This value is given by multiplying the output of water specified in equation (1) or $q_{p}^{1}$ by the price of water $p$. This gives us

12

We use the logarithmic production function because it is straightforward to work with and yields analytical results. In addition, there are several precedents---see Mayumi and Giampietro (2010) and Mehmood et al. (2015)---for using either the logarithmic function or variants of the logarithmic function to model and study the production of a pertinent variable. 13

See Tadelis (2013, pp. 43-126) for a textbook exposition of static games. 


$$
p q_{p}^{1}=p \log \left(\tau_{p}^{1}\right)
$$

where the superscript 1 refers to farmer 1 . After farmer 2 has stolen water from farmer 1 , the value of farmer 1's output of water is reduced to

$$
\left\{1-\frac{\zeta \tau_{t}^{2}}{T}\right\} p \log \left(\tau_{p}^{1}\right)
$$

where the superscript 2 refers to farmer 2 and $\zeta \tau_{t}^{2} / T$ denotes the proportion of farmer 1's water that is stolen by farmer 2 . The value of the water stolen by farmer 1 from farmer 2 is

$$
\left\{\frac{\zeta \tau_{t}^{1}}{T}\right\} p \log \left(\tau_{p}^{2}\right)
$$

Putting the information in equations (2) through (4) together, farmer 1's wealth $\left(W^{1}\right)$ from water production and theft can be written as

$$
W^{1}=\left\{1-\frac{\zeta \tau_{t}^{2}}{T}\right\} \operatorname{plog}\left(\tau_{p}^{1}\right)+\left\{\frac{\zeta \tau_{t}^{1}}{T}\right\} \operatorname{plog}\left(\tau_{p}^{2}\right)
$$

A line of reasoning very similar to that employed thus far in this section for farmer 1 tells us that farmer 2's wealth $\left(W^{2}\right)$ from water production and theft is given by 


$$
W^{2}=\left\{1-\frac{\zeta \tau_{t}^{1}}{T}\right\} p \log \left(\tau_{p}^{2}\right)+\left\{\frac{\zeta \tau_{t}^{2}}{T}\right\} \log \left(\tau_{p}^{1}\right)
$$

Inspecting equations (5) and (6) we see that the wealth of the two farmers is given by a weighted sum of the times spent producing and stealing water. The weights themselves are the terms shown in the curly brackets in these two equations. The above features of our model are described in tabular form in the first four rows of Figure 1. The first row marked "Players" lists the two players

\section{Figure 1 about here}

in the static game that we are studying. The second row marked "Main variables" lists the main exogenous $(T)$ and endogenous $\left(\tau_{p}^{k}, \tau_{t}^{k}, k=1,2\right)$ variables. The third row marked "Farmer objective" notes that the goal of both farmers is to maximize their wealth for producing and stealing water. The fourth row marked "Solution concept" points out that we are interested in the behavior of the two farmers in a symmetric Nash equilibrium.

The use of time by each of the two farmers is constrained by the fact that the total available time $(T)$ is spent either producing or stealing water. In symbols, this gives us

$$
T=\tau_{p}^{k}+\tau_{t}^{k}, k=1,2
$$

Let us now substitute the time spent stealing water or $\tau_{t}^{k}$ from equation (7) into the two objective functions given in equations (5) and (6). Doing this, the wealth maximization problems faced by farmers 1 and 2---also see the third row of Figure 1 marked "Farmer objective"---can be rewritten 


$$
\max _{\left\{\tau_{p}^{1}\right\}} W^{1}=\left\{1-\frac{\zeta\left(T-\tau_{p}^{2}\right)}{T}\right\} \operatorname{plog}\left(\tau_{p}^{1}\right)+\left\{\frac{\zeta\left(T-\tau_{p}^{1}\right)}{T}\right\} \operatorname{plog}\left(\tau_{p}^{2}\right)
$$

and

$$
\max _{\left\{\tau_{p}^{2}\right\}} W^{2}=\left\{1-\frac{\zeta\left(T-\tau_{p}^{1}\right)}{T}\right\} p \log \left(\tau_{p}^{2}\right)+\left\{\frac{\zeta\left(T-\tau_{p}^{2}\right)}{T}\right\} \operatorname{plog}\left(\tau_{p}^{1}\right)
$$

The reader should note that when maximizing the objective functions in equations (8) and (9), each farmer takes the choice made by the other farmer as given.

Now, to find the Nash equilibrium of the game between farmers 1 and 2, we differentiate the maximands in equations (8) and (9) with respect to the two choice or decision variables $\tau_{p}^{1}$ and $\tau_{p}^{2}$, and then set the resulting expressions equal to zero. The first-order necessary condition for an optimum for farmer 1 , for instance, is

$$
\left\{1-\frac{\zeta\left(T-\tau_{p}^{2}\right)}{T}\right\} \frac{p}{\tau_{p}^{1}}-\left\{\frac{\zeta}{T}\right\} \operatorname{plog}\left(\tau_{p}^{2}\right)=0
$$

Equation (10) can also be thought of as farmer 1's best response or reaction function. As noted in section 2 , the two farmers are very similar in terms of their abilities to both produce and steal 
water. Therefore, we look for a symmetric Nash equilibrium---also see the fourth row of Figure 1 marked "Solution concept"---in which we have

$$
\tau_{p}^{1}=\tau_{p}^{2}=\tau_{n}
$$

where $\tau_{n}$ is the Nash equilibrium amount of time spent producing water by each of the two farmers. Substituting the result in equation (11) into the first-order necessary condition in equation (10) gives us

$$
(1-\zeta) T+\zeta \tau_{n}\left\{1-\log \left(\tau_{n}\right)\right\}=0
$$

Equation (12) implicitly characterizes the Nash equilibrium amount of time spent producing water by the two farmers under study. We now proceed to discuss how this equilibrium is impacted by a change in the ease with which water can be stolen by either of the two farmers.

\section{Impact of the Ease of Theft on the Nash Equilibrium}

Recall from section 2 that the ease with which water can be stolen by either farmer is described by the parameter $\zeta$. So, in symbols, what we want to know is how $\tau_{n}$ changes when $\zeta$ increases by a small amount.

To answer this question, let us totally differentiate equation (12) with respect to $\tau_{n}$ and $\zeta$. After differentiation, we obtain $\zeta \log \left(\tau_{n}\right) d \tau_{n}=-\left[T-\tau_{n}\left\{1-\log \left(\tau_{n}\right)\right\}\right] d \zeta$. This last expression can be simplified to

$$
\frac{d \tau_{n}}{d \zeta}=-\frac{T-\tau_{n}\left\{1-\log \left(\tau_{n}\right)\right\}}{\zeta \log \left(\tau_{n}\right)} .
$$


Let us now use equation (12) to substitute for $\left\{1-\log \left(\tau_{n}\right)\right\}$ in equation (13). Doing this, the ratio on the right-hand-side (RHS) of equation (13) simplifies to

$$
\frac{d \tau_{n}}{d \zeta}=-\frac{T}{\zeta^{2} \log \left(\tau_{n}\right)}
$$

Inspecting equation (14), it should be clear to the reader that there are two cases to consider. To this end, suppose first that the optimal value of $\tau_{n}$ that emerges from solving equation (12) is such that $\tau_{n}>1$. In this case, $\log \left(\tau_{n}\right)>0$ and $d \tau_{n} / d \zeta<0$. This is the intuitively meaningful case. In words, this result tells us that as it becomes easier to steal water $(\zeta \uparrow)$, the amount of time allocated to producing water or $\tau_{n}$ declines $\left(\tau_{n} \downarrow\right)$. However, this is not the only possibility. If, in contrast, the solution of equation (12) gives us $\tau_{n}<1$ then $d \tau_{n} / d \zeta>0$ is possible and counterintuitively, this result tells us that for a certain region in the parameter space, even though stealing water becomes simpler, it still makes sense to allocate more time to producing and not stealing water. ${ }^{14}$ These findings are also delineated succinctly in the fifth row of Figure 1 marked "Impact of change in ease of theft." Our final task is to show how the section 3 Nash equilibrium is impacted when there is no water theft. We then compute the maximum amount that a farmer would be willing to pay to prevent theft. 


\section{Willingness to Pay to Preclude Theft}

If there is no theft of water then both farmers will be allocating all their time to the production of water. This means that $\tau_{n}=T$. Now, let $\mathrm{M}$ be the maximum amount that either farmer is willing to pay to avoid water theft. Then, some thought tells us that this maximum amount is equal to the payoff without water theft $\left(\mathrm{M}^{w o}\right)$ less the payoff with water theft $\left(M^{w}\right)$. In symbols, we have $\mathrm{M}=\mathrm{M}^{\text {wo }}-\mathrm{M}^{w}$.

Inspecting equations (5) and (6) and keeping $\tau_{n}=T$ in mind, it is straightforward to confirm two points. First, the payoff to either farmer without water theft or $\mathrm{M}^{\text {wo }}=p \log (T)$. Second and in contrast, the payoff with water theft is given by

$$
\mathrm{M}^{w}=\left\{1-\frac{\zeta\left(T-\tau_{n}\right)}{T}\right\} \operatorname{plog}\left(\tau_{n}\right)+\left\{\frac{\zeta\left(T-\tau_{n}\right)}{T}\right\} \operatorname{plog}\left(\tau_{n}\right)
$$

Therefore, combining the preceding two results, the maximum willingness to pay to avoid water theft is $\mathrm{M}=\mathrm{M}^{w o}-\mathrm{M}^{w}$ or

$$
\mathrm{M}=\operatorname{plog}(T)-\left\{1-\frac{\zeta\left(T-\tau_{n}\right)}{T}\right\} p \log \left(\tau_{n}\right)-\left\{\frac{\zeta\left(T-\tau_{n}\right)}{T}\right\} \operatorname{plog}\left(\tau_{n}\right)
$$

The expression on the RHS of equation (16) can be simplified further. This simplification gives $M=p\left\{\log (T)-\log \left(\tau_{n}\right)\right\}$. Manipulating this last expression, we obtain 


$$
\mathrm{M}=\operatorname{plog}\left(\frac{T}{\tau_{n}}\right)
$$

Inspecting equation (17), we see that the maximum willingness to pay to avoid water theft is an increasing function of the exogenously given price of water $(p)$ and a decreasing function of the equilibrium amount of time spent producing water $\left(\tau_{n}\right)$. These two results make sense in the context of the theoretical inquiry that we are conducting in this paper. Specifically, and as shown in the sixth row of Figure 1 marked "Maximum willingness to pay to avoid theft," the first result tells us that as water becomes more valuable $(p \uparrow)$, farmers are willing to pay more $(\mathrm{M} \uparrow)$ to avoid the theft of their water. The second result says that as the amount of time spent producing water by a farmer rises $\left(\tau_{n} \uparrow\right)$, there is less time to steal water from the other farmer and hence water theft becomes a less salient issue. Therefore, farmers are now willing to pay less $(M \downarrow)$ to avoid water theft.

We now comment on some of the benefits that arise from our use of a game-theoretic model to analyze the problem of water theft by farmers during a drought. The first benefit is that we have an explicit way of modeling and studying how strategic considerations affect the payoffs accruing to the players in the game. In our paper this is clear from the fact that the wealth function of farmer 1---see equations (5) and (6)---depends on the action taken by farmer 2 and vice versa. The second benefit is that we are able to shed light on how exogenous factors influence both the choices and the payoffs accruing to the two farmers. In our case, the exogenous factor of greatest interest is the effortlessness with which water can be stolen by either farmer. Finally, by computing an explicit expression for the maximum willingness to pay to avoid water theft, our model shows which 
variables a policymaker will need to concentrate on to design an incentive scheme such as a monetary payment mechanism to discourage farmers from stealing water from each other.

A game-theoretic model of the sort utilized in this paper can be used gainfully to analyze circumstances in which the payoffs accruing to the farmers are interdependent, where each farmer is affected by the optimizing behavior of the other farmer, and where neither farmer is able to act as a "leader" ("follower") with the other farmer acting as a "follower" (leader"). We were able to obtain explicit solutions for the endogenous variables of interest because of the assumptions we employed such as the static nature of the interaction between the two farmers and the use of a logarithmic function to model the production of water. As such, if the assumptions of our model do not hold or when the number of farmers interacting with each other is large, our model may become unwieldy to work with and, in addition, may not yield closed-form solutions. This completes our analysis of a game-theoretic model of water theft during a drought.

\section{Conclusions}

In this paper, we studied water use by two geographically proximate farmers in a particular region during a drought. The two farmers each had an endowment of time that could be used either to produce water or to steal water. The price of water was exogenously given. The goal of the two farmers was to maximize their wealth from water production and water theft. In this setting, we performed three tasks. First, we determined the symmetric Nash equilibrium of the game-theoretic interaction between the two farmers. Second, we analyzed how this equilibrium depended on the ease with which water could be stolen. Finally, we pointed out that if there was no water theft then both famers would spend all of the available time producing water. This fact allowed us to compute a closed-form expression for the maximum willingness to pay on the part of the two farmers to avoid water theft. In this way, we demonstrated how the symmetric Nash equilibrium was 
impacted when there was no water theft and then we noted that the trinity of (i) the price of water, (ii) the available time endowment of each farmer, and (iii) the amount of time spent producing water, determined the maximum amount that a farmer would be willing to pay to prevent theft.

The analysis in this paper can be extended in a number of different directions. Here are three suggestions for extending the research described here. First, the analysis we conducted in this paper assumed that the parameter values were such that a symmetric Nash equilibrium existed. Therefore, in a more exhaustive analysis, one could study the existence of potential corner solutions and asymmetric Nash equilibria. Second, it would be helpful to explicitly introduce law enforcement into the analysis and to then study how the enforcement of laws designed to preclude water theft influences the behavior of drought affected farmers. Finally, it would be useful to determine what kind of results about water theft are obtainable when one uses what Oladi (2005) calls an "alternating retaliation or theft" setup. Studies that analyze these aspects of the underlying problem will increase our understanding of issues concerning water use by farmers during a time of scarcity brought about by a drought. 


\begin{tabular}{|c|c|c|}
\hline Players & Farmer 1 & Farmer 2 \\
\hline Main variables & $\begin{array}{l}\text { Time endowment } T \text {, time } \\
\text { producing, stealing } \tau_{p}^{1}, \tau_{t}^{1}\end{array}$ & $\begin{array}{l}\text { Time endowment } T \text {, time } \\
\text { producing, stealing } \tau_{p}^{2}, \tau_{t}^{2}\end{array}$ \\
\hline \multicolumn{3}{|c|}{$\overline{\nabla \nabla \nabla}$} \\
\hline Farmer objective & $\begin{array}{l}\text { Maximize wealth } W^{1} \text { from } \\
\text { producing and stealing }\end{array}$ & $\begin{array}{l}\text { Maximize wealth } W^{2} \text { from } \\
\text { producing and stealing }\end{array}$ \\
\hline \multicolumn{3}{|c|}{$\nabla \nabla \nabla$} \\
\hline Solution concept & $\begin{array}{c}\text { Symmetric Nash equilibrium, } \\
\text { time producing } \tau_{n}\end{array}$ & $\begin{array}{c}\text { Symmetric Nash equilibrium, } \\
\text { Time producing } \tau_{n}\end{array}$ \\
\hline \multicolumn{3}{|c|}{$\nabla \nabla \nabla$} \\
\hline $\begin{array}{c}\text { Impact of change in ease of } \\
\text { theft }(\zeta \uparrow)\end{array}$ & $\begin{array}{l}\text { Intuitive case: time producing } \\
\qquad \tau_{n} \downarrow \\
\frac{\text { Counterintuitive case: time }}{\text { producing } \tau_{n} \uparrow}\end{array}$ & $\begin{array}{l}\text { Intuitive case: time producing } \\
\qquad \tau_{n} \downarrow \\
\frac{\text { Counterintuitive case: time }}{\text { producing } \tau_{n} \uparrow}\end{array}$ \\
\hline \multicolumn{3}{|c|}{$\nabla \nabla \nabla$} \\
\hline $\begin{array}{l}\text { Maximum willingness to pay } \\
\text { to avoid theft }(M)\end{array}$ & $\begin{array}{c}\mathrm{M}=\operatorname{plog}\left(T / \tau_{n}\right) \\
\mathrm{p} \uparrow \Rightarrow \mathrm{M} \uparrow, \tau_{n} \uparrow \Rightarrow \mathrm{M} \downarrow\end{array}$ & $\begin{array}{c}\mathrm{M}=\operatorname{plog}\left(T / \tau_{n}\right) \\
\mathrm{p} \uparrow \Rightarrow \mathrm{M} \uparrow, \tau_{n} \uparrow \Rightarrow \mathrm{M} \downarrow\end{array}$ \\
\hline
\end{tabular}

Figure 1: Key features of the water production and theft game model 


\section{References}

Baird, A., and Walters, R. 2020. Water theft through the ages: Insights for green criminology, Critical Criminology, 28, 371-388.

Brisman, A., McClanahan, B., South, N., and Walters, R. 2018. Water, Crime and Security in the Twenty-First Century. Palgrave Macmillan, London, UK.

Galaz, V. 2004. Stealing from the poor? Game theory and the politics of water markets in Chile, Environmental Politics, 13, 414-437.

Khokha, S. 2015. The next crime wave in farm country: Stealing water, KQED Science, https://www.kqed.org/science/29094/the-next-crime-wave-in-farm-country-stealingwater. Accessed on 25 May 2021.

Knox, J., Morris, J., Hess, T. 2010. Identifying future risks to UK agricultural crop production: Putting climate change in context, Outlook on Agriculture, 39, 249-256.

Loch, A., Perez Blanco, C.D., Carmody, E., Felbab-Brown, V., Adamson, D., and Seidl, C. 2020. Grand theft water and the calculus of compliance, Nature Sustainability, 3, 1012-1018.

Lowdermilk, M.K. 1990. Irrigation water control and anarchy, in R.K. Sampath and R.A. Young, (Eds.), Social, Economic, and Institutional Issues in Third World Irrigation Management. Westview Press, 155-173. Boulder, CO.

Mayumi, K., and Giampietro, M. 2010. Dimensions and logarithmic function in economics: A short critical analysis, Ecological Economics, 69, 1604-1609. 
Mehmood, B., Nisar, A., and Rehman, H.U. 2015. Technology matters: Evidence from Pakistani banking sector using flexible transcendental logarithmic production function, Pakistan Economic and Social Review, 53, 203-224.

Meinzen-Dick, R. 2014. Property rights and sustainable irrigation: A developing country perspective, Agricultural Water Management, 145, 23-31.

Nash, J. 1951. Non-cooperative games, Annals of Mathematics, 54, 286-295.

Oladi, R. 2005. Stable tariffs and retaliations, Review of International Economics, 13, 205-215.

Podimata, M.V., and Yannopoulos, P.C. 2015. Evolution of game theory application in irrigation systems, Agriculture and Agricultural Sciences Procedia, 4, 271-281.

Pradhan, R., and Pradhan, U. 2000. Negotiating access and rights: Disputes over rights to an irrigation water source in Nepal, in B.R. Bruns and R.S. Meinzen-Dick, (Eds.), Negotiating Water Rights. Intermediate Technology Press, 200-221. London, UK.

Ray, I., and Williams, J. 1999. Evaluation of price policy in the presence of water theft, American Journal of Agricultural Economics, 81, 928-941.

Ray, I., and Williams, J. 2002. Locational asymmetry and the potential for cooperation on a canal, Journal of Development Economics, 67, 129-155.

Rey, D., Holman, I.P., and Knox, J.W. 2017. Developing drought resilience in irrigated agriculture in the face of increasing water scarcity, Regional Environmental Change, 17, 1527-1540.

Sampaio Morais, G.A., Silvo, F.F., de Freitas, C.O., and Braga, M.J. 2021. Irrigation, technical efficiency, and farm size: The case of Brazil, Sustainability, 13, 1132. 
Tadelis, S. 2013. Game Theory. Princeton University Press, Princeton, NJ.

Tilahan, H., Erkossa, T., Michael, M., Hagos, F.G., and Awlachew, S.B. 2011. Comparative performance of irrigated and rainfed agriculture in Ethiopia, World Applied Sciences Journal, 14, 235-244.

Viellaris, R. 2019. Farmers stealing water; turning on each other in drought, The Toowoomba Chronicle, Australia, https://www.questia.com/newspaper/1G1-601205283/farmersstealing-water-turning-on-each-other-in-drought. Accessed on 24 May 2021.

Wilhite D. 2007. Preparedness and coping strategies for agricultural drought risk management: Recent progress and trends, in M.V.K. Sivakumar and R.P. Motha, (Eds.), Managing Weather and Climate Risks in Agriculture, 21-38. Springer, New York, NY. 